\title{
Diagnostics of autoimmune bullous diseases in German dermatology departments
}

Nina van Beek ${ }^{1}$, Diana Knuth- Rehr ${ }^{2}$, Peter Altmeyer ${ }^{3}$, Chalid Assaf $^{4}$, Philipp Babilas ${ }^{5}$, Christiane Bayerl ${ }^{6}$, Sandrine Benoit ${ }^{7}$, Edgar Dippel ${ }^{8}$, Isaak Effendy ${ }^{9}$, Rüdiger Eming ${ }^{10}$, Matthias Fischer ${ }^{11}$, Thomas Glaenz $^{12}$, Regine Gläser ${ }^{13}$, Matthias Goebeler ${ }^{14}$, Harald Gollnick ${ }^{15}$, Steven Götze ${ }^{16}$, Gerd Gross ${ }^{17}$, Eva Hadaschik ${ }^{18}$, Rudolf Herbst ${ }^{19}$, Barbara Hermes ${ }^{20}$, Bernhard Homey ${ }^{21}$, Nico Hunzelmann ${ }^{22}$, Michael Jünger ${ }^{23}$, Alexander Kapp ${ }^{24}$, Johannes S. Kern ${ }^{25}$, Andreas Körber ${ }^{26}$, Thomas Luger ${ }^{27}$, Dirk Mechtel ${ }^{28}$, Mosaad Megahed ${ }^{29}$, Ingrid Moll ${ }^{30}$, Klaus-Peter Peters ${ }^{31}$, Christiane Pfeiffer ${ }^{32}$, Johannes Ring ${ }^{33}$, Martin Röcken ${ }^{34}$, Miklós Sárdy ${ }^{35}$, Cornelia S. Seitz ${ }^{36}$, Rudolf Stadler ${ }^{37}$, Kerstin Steinbrink ${ }^{38}$, Michael Sticherling ${ }^{39}$, Rolf-Markus Szeimies ${ }^{40}$, Michael Tronnier ${ }^{41}$, Jens Ulrich ${ }^{42}$, Thomas Vogt ${ }^{43}$, Nicola Wagner ${ }^{44}$, Julia Welzel ${ }^{45}$, Jörg Wenzel ${ }^{46}$, Gottfried Wozel ${ }^{47}$, Christos C. Zouboulis ${ }^{48}$, Detlef Zillikens ${ }^{1}$, Enno Schmidt ${ }^{1,2}$

With the exception of the first two and last authors in alphabetical order.

(1) Department of Dermatology, Allergology and Venereology, University of Lübeck

(2) Institute for Systemic Inflammation Research, University of Lübeck

(3) Department of Dermatology and Allergology, University of Bochum

(4) Dermatology Clinic, HELIOS Clinic, Krefeld

(5) Department of Dermatology, University of Regensburg

(6) Department of Dermatology and Allergology, Dr. Horst Schmidt Clinics, Wiesbaden

(7) Department of Dermatology, Venereology and Allergology, University of Würzburg

(8) Dermatology Clinic Ludwigshafen

(9) Department of Dermatology, Municipal Clinic of Bielefeld

(10) Department of Dermatology, University of Marburg

(11) Department of Dermatology and Venereology, HELIOS Clinic Aue

(12) PsoriSol Dermatology Clinic, Hersbruck

(13) Department of Dermatology, Allergology and Venereology, University of Kiel

(14) Department for Dermatology, Venereology and Allergology, University of Gießen

(15) Department of Dermatology and Venereology, University of Magdeburg

(16) Department of Dermatology and Allergology, University of Jena

(17) Department of Dermatology and Venereology, University of Rostock

(18) Department of Dermatology, University of Heidelberg

(19) Department of Dermatology and Allergolgoy, HELIOS Clinic Erfurt

(20) Department of Dermatology and Phlebology, Vivantes Clinic Friedrichshain, Berlin

(21) Department of Dermatology, University of Düsseldorf

(22) Department of Dermatology and Venereology, University of Köln

(23) Department of Dermatology, University of Greifswald

(24) Department of Dermatology, Allergology and Venerology, Hannover Medical School

(25) Department of Dermatology, University of Freiburg

(26) Department of Dermatology, University of Essen

(27) Department of Dermatology, University of Münster

(28) Department of Dermatology and Allergology, Heinrich Braun Clinic Zwickau

(29) Department of Dermatology, University of Aachen

(30) Department of Dermatology and Venereology, University Clinic of Eppendorf, Hamburg

(31) Department of Dermatology, Bayreuth Hospital, Bayreuth

(32) Department of Dermatology and Alergology, University of UIm

(33) Department of Dermatology and Allergology, Technical University of Munich

(34) Department of Dermatology, University of Tübingen

(35) Department of Dermatology and Allergology, Ludwig Maximilian University of Munich

(36) Department of Dermatology, Venereology and Allergology, University of Göttingen

(37) Department of Dermatology, Johannes Wesling Clinic, Minden

(38) Department of Dermatology, University of Mainz

(39) Department of Dermatology, University of Erlangen

(40) Department of Dermatology and Allergology, Vest Clinic-Miners' Hospital, Recklinghausen

(41) Department of Dermatology, Venereology and Allergology, Hildesheim Clinic, Hildesheim

(42) Department of Dermatology and Allerogology, Erxleben Clinic, Quedlinburg

(43) Department of Dermatology, Venereology and Allergology, University of the Saarland, Homburg/Saar

(44) Department of Dermatology, Darmstadt Hospital, Darmstadt 
(45) Department of Dermatology, Augsburg Hospital, Augsburg

(46) Department of Dermatology and Allergology, University of Bonn

(47) Department of Dermatology, University of Dresden

(48) Department of Dermatology, Venereology and Allergology/ Immunological Center, Municipal Clinic of Dessau (all Germany)

Data were summarized ( $<120$ words) in [37].

Keywords

- autoantibody

- bullous pemphigoid

- ELISA

- immunoblot

- immunofluorescence

- pemphigus

\section{Introduction}

Autoimmune bullous dermatoses represent a broad spectrum of about one dozen different diseases. In Germany, bullous pemphigoid (BP) is by far the most common autoimmune bullous disorder with an incidence of 13.4 new cases/ million yearly. Pemphigoid gestationis and mucous membrane pemphigoid are the second most frequent diseases with 2.0/ million/ year [1]. The incidence of pemphigus in Germany is about $1.0 /$ million/ year [2]. Thus, about 2500 new cases of autoimmune bullous diseases can be expected in Germany per year. As the incidence of BP increases significantly with age up to 150-190/ million/ year in over 80-year-old patients $[1,3]$, a growing number of patients and thus an increased need for diagnostics is to be anticipated.

Clinically, the pemphigoid diseases are characterized by tense blisters and ero-

\section{Summary}

Background: No consistent data are available on the currently employed diagnostic tools for autoimmune bullous diseases in Germany. The aim of this survey was to describe currently performed diagnostic methods for bullous autoimmune diseases in German dermatology departments.

Methods: A standardized questionnaire evaluated the available diagnostic methods i. e. direct immunofluorescence microscopy (IFM), indirect IFM, commercial ELISA systems, and non-commercial serological tests as well as the number of samples per year in all 34 university and 39 non-university dermatology departments.

Results: The overall return rate was $89 \%, 100 \%$ and $79 \%$ for the university and non-university departments, respectively. Direct IFM was the most frequently used method and was applied in $98 \%$ of the responding departments. In $74 \%$ of the responding departments, indirect IFM was used mainly on monkey esophagus and human salt-split skin. Commercial ELISA systems were employed in $58 \%$ of the clinics; all of them used anti-desmoglein ELISA, while anti-BP180 and anti-BP230 ELISA were established in $49 \%$ and $48 \%$ of departments, respectively. Non-commercial analytic methods were only performed in $22 \%$ of the departments.

Conclusions: The high return rate of this survey allows a relatively precise description of the current diagnostic methods used in German dermatology departments. Standard diagnostic tests are available nationwide and in bullous pemphigoid and pemphigus, the antigen-specific detection of autoantibodies is routinely performed in half of the departments. Rare disorders may be diagnosed by cooperation with some specialized centers.

sions of the skin, mucous membrane pemphigoid by erosion of mucous membranes near the skin surface $[4,5]$. Pemphigus vulgaris is always associated with mucous membrane lesions, while pemphigus foliaceus typically presents with erosions and scales in seborrheic areas. Clinically, the various entities cannot be definitely differentiated from each other. E.g., the differentiation between pemphigus vulgaris and mucous membrane pemphigoid on the one hand and between BP, anti-p200/ laminin $\gamma 1$ pemphigoid and epidermolysis bullosa acquisita on the other is often difficult. In addition, premonitory BP is clinically indistinguishable from other puritic skin diseases. For these cases direct immunofluorescence (IF) microscopy of a perilesional skin biopsy is essential. The exact differentiation of the individual entities is both of prognostic and therapeutic significance. Thus, anti-laminin $332 \mathrm{mu}$ - cous membrane pemphigoid is associated with malignancy in $30 \%$ of patients and anti-p200/ laminin $\gamma 1$ pemphigoid is usually easier to treat than BP, while epidermolysis bullosa acquisita is distinctly more difficult to influence than BP. In addition to direct IF microscopy, serological diagnostics adapted to the clinical situation is indispensible today [6-10]. With the description of further target antigens and their significance for prognosis and therapeutic measures, the need for antigen-specific diagnostics will further increase in the future. The aim of the present study was to portray diagnostics of autoimmune bullous dermatoses available in German departments of dermatology.

\section{Materials and methods}

A standardized questionnaire was sent to all 34 German university departments of dermatology and 39 non-university 
Questionnaire on the care of patients with autoimmune bullous dermatoses in Germany

Which methods for diagnosing autoimmune bullous dermatoses do you employ in your clinic?

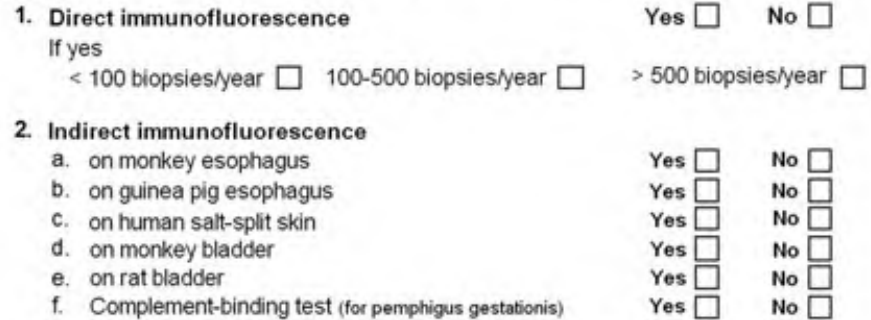

2. Indirect immunofluorescence

a. on monkey esophagus

b. on guinea pig esophagus

c. on human salt-split skin

d. on monkey bladder

e. on rat bladder

f. Complement-binding test (for pemphigus gestationis)

How many sera are examined using indirect immunofluorescence?
$<100$ year $\square$

100-500/year $\square$

3. Commercial ELISA systems

a. BP180 NC16A

b. $B P 230$

c. Desmoglein 1

d. Desmoglein 3

e. Envoplakin

How many sera are examined using commercial ELISA systems?

$<$ 100/year $\square \quad$ 100-500/year $\square$ 501-1000/year $\square$

4. Non-commercial immunoblot/ELISA systems

a. BP180

b. $B P 230$

c. LAD-1 (soluble BP 180 ectodomain)

d. Epitopes on BP180 outside of the NC16A domain

e. Laminin 332 (taminin 5)

f. Type VII collagen

g. NC1 domain of type VII collagen

h. p200 protein

i. Laminin $y 1$

j. a6 integrin

k. $\beta 4$ integrin

1. Desmoplakin I/II

m. Periplakin

n. Envoplakin
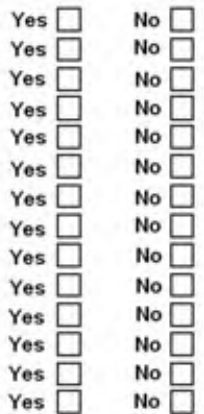

How many tests using non-commercial test systems are performed annually?

$<100 /$ year $\square \quad$ 100-500/year $\square \quad$ 500-1000/year $\square \quad>1000 /$ year $\square$

Figure 1: Standardized questionnaire about the diagnostic methods at German dermatology departments.

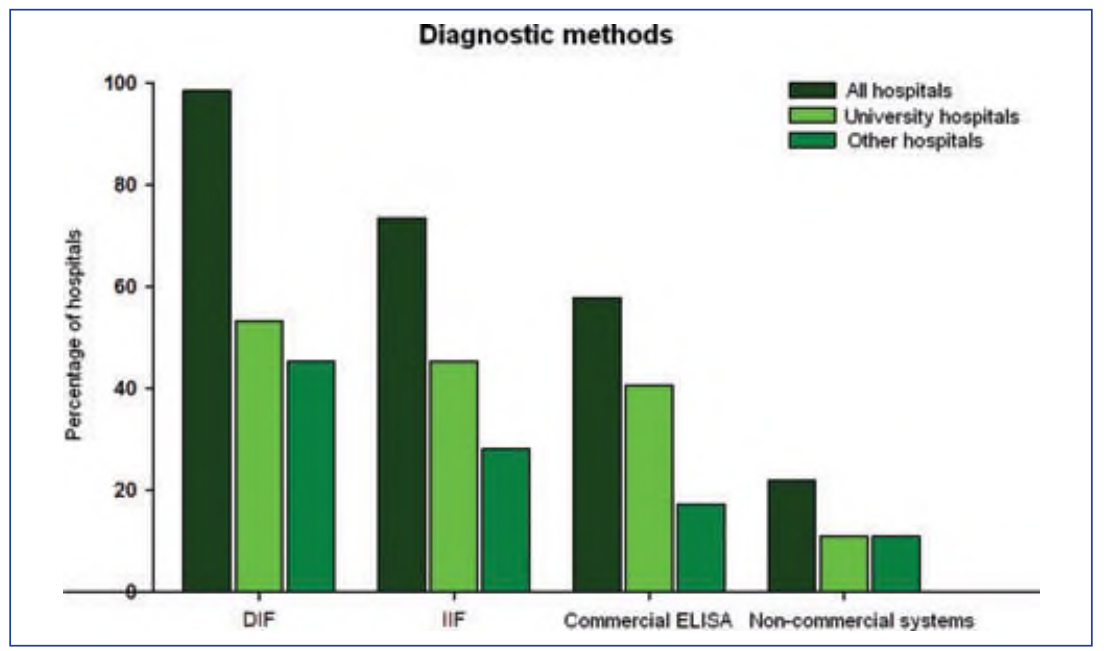

Figure 2: Percentage of German dermatology departments that perform direct immunofluorescence microscopy (DIF), indirect immunofluorescence microscopy (IIF), commercially available ELISA systems, and non-commercial assays for the diagnosis of autoimmune bullous skin diseases. The percentages of university (light green) and non-university hospitals (green) are related to the percentage of investigations performed in all hospitals (dark green). dermatology hospitals (Figure 1). The questionnaire included four questions to be answered in a dichotomous manner (yes/no) on diagnostic methods employed for autoimmune bullous dermatoses: (i) direct IF microscopy, (ii) indirect IF microscopy on monkey esophagus, guinea pig esophagus, human salt-split skin, monkey bladder, rat bladder and complement-binding test on human salt-split skin, (iii) commercially available ELISA for detection of autoantibodies against BP180 NC16A, BP230, desmoglein 1, desmoglein 3 and envoplakin and (iv) non-commercial assays including ELISA and immunoblot techniques for autoantibodies against BP180, BP230, the soluble ectodomain of BP180 (LAD-1), epitopes on BP180 outside of the BP180 NC16A domain, laminin 332, type VII collagen, p200 protein, laminin $\gamma 1, \alpha 6$ integrin, $\beta 4$ integrin, desmoplakin I and II, periplakin and envoplakin. The number of annually analyzed samples for each of the studied complexes were to be checked in predetermined categories $(<100,100-500$, 501-1 000, and perhaps > $1000 /$ year). A numerical analysis of the survey followed.

\section{Results}

All of the 34 (100\%) university departments of dermatology and 31 of the 39 (79 \%) of non-university dermatology clinics returned the questionnaire. All returned questionnaires could be evaluated, producing an overall return rate of $89 \%$. An overview of the 4 recorded diagnostic techniques (direct and indirect IF microscopy, commercial ELISA, non-commercial ELISA/ immunoblots) is depicted in Figure 2.

\section{Direct immunofluorescence}

Direct IF microscopy is performed in practically all departments of dermatology (all university departments and 30 of the 31 non-university dermatology clinics) (Figure 3). Direct IF microscopy was not only the most widespread diagnostic method, but was also performed most frequently. Of the clinics $51 \%$ performed 100-500 and $18 \%$ more than 500 analyses yearly (10 of the university departments and 3 of the non-university clinics) (Figure 5a).

\section{Indirect immunofluorescence}

Tests using indirect IF microscopy were performed in $74 \%$ of all clinics (30 of 


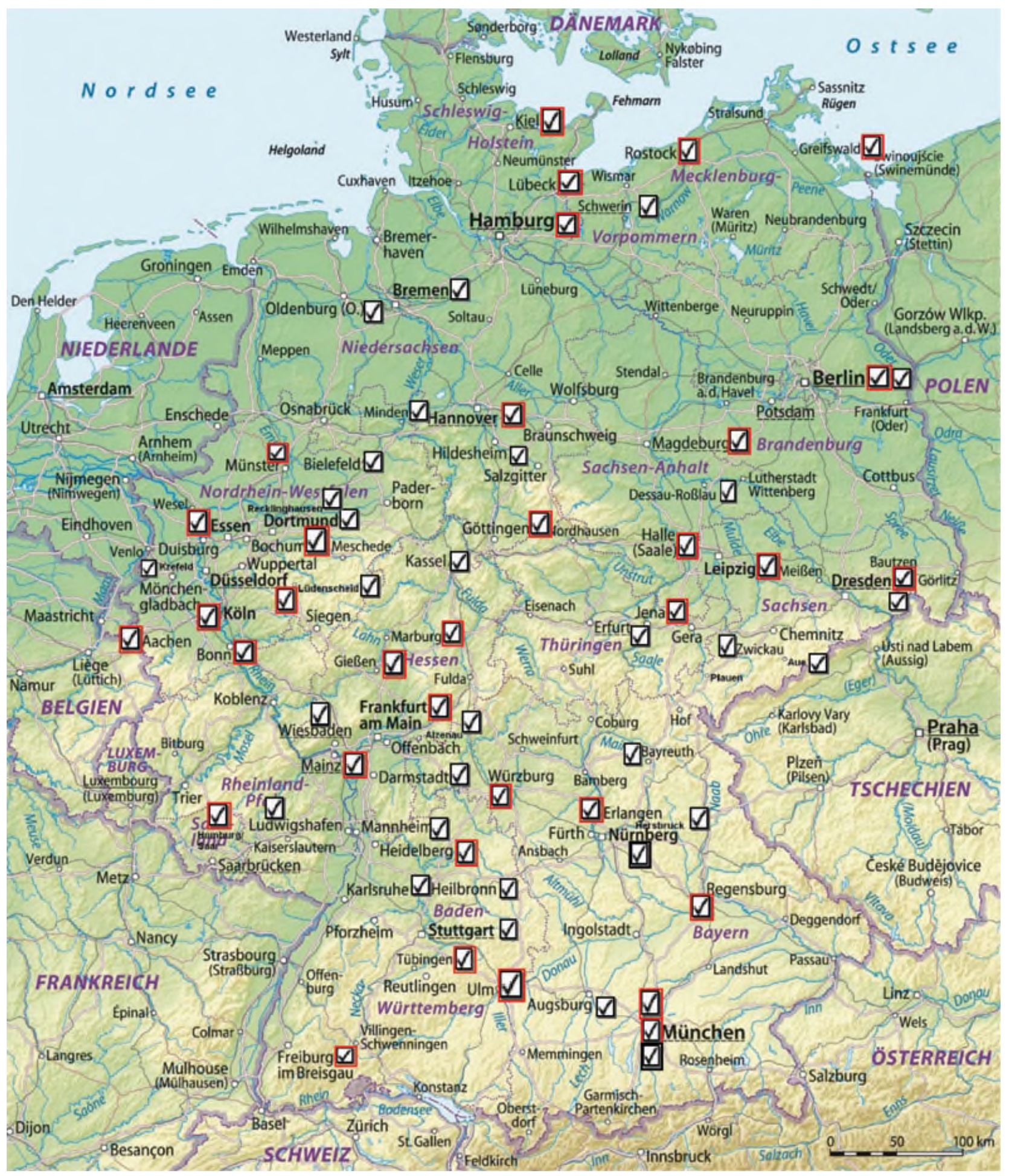

Figure 3: Geographic overview of university (red box) and non-university dermatology departments (black box) that perform direct immunofluorescence microscopy. (Licence: [http://creativecommons.org/licenses/by-sa/3.0/de/ GNU-Lizenz für freie Dokumentation]).

the 34 university departments and 18 of the 31 non-university clinics). The most common substrate in these 48 departments of dermatology was monkey esophagus $(83 \%)$ and human salt-split skin $(65 \%)$ (Figure 4a). Indirect IF microscopy on monkey or rat bladder and the complement-binding test on human salt-split skin was performed predominantly in the university departments (57\% or $27 \%$, respectively, as opposed to $11 \%$ in non-university clinics) (Figure 4a).

Commercial ELISA

Commercial ELISA were available in 26 of $34(76 \%)$ university departments of dermatology and in 12 of 31 (38\%) nonuniversity dermatology clinics (on the whole $58 \%$ of clinics). ELISA for anti-desmoglein 1 and 3 antibodies were employed in all 38 clinics, ELISA for anti-BP180 and anti-BP230 antibodies in $84 \%$ or $82 \%$ of these 38 clinics, respectively (Figure 4b). With respect to the 


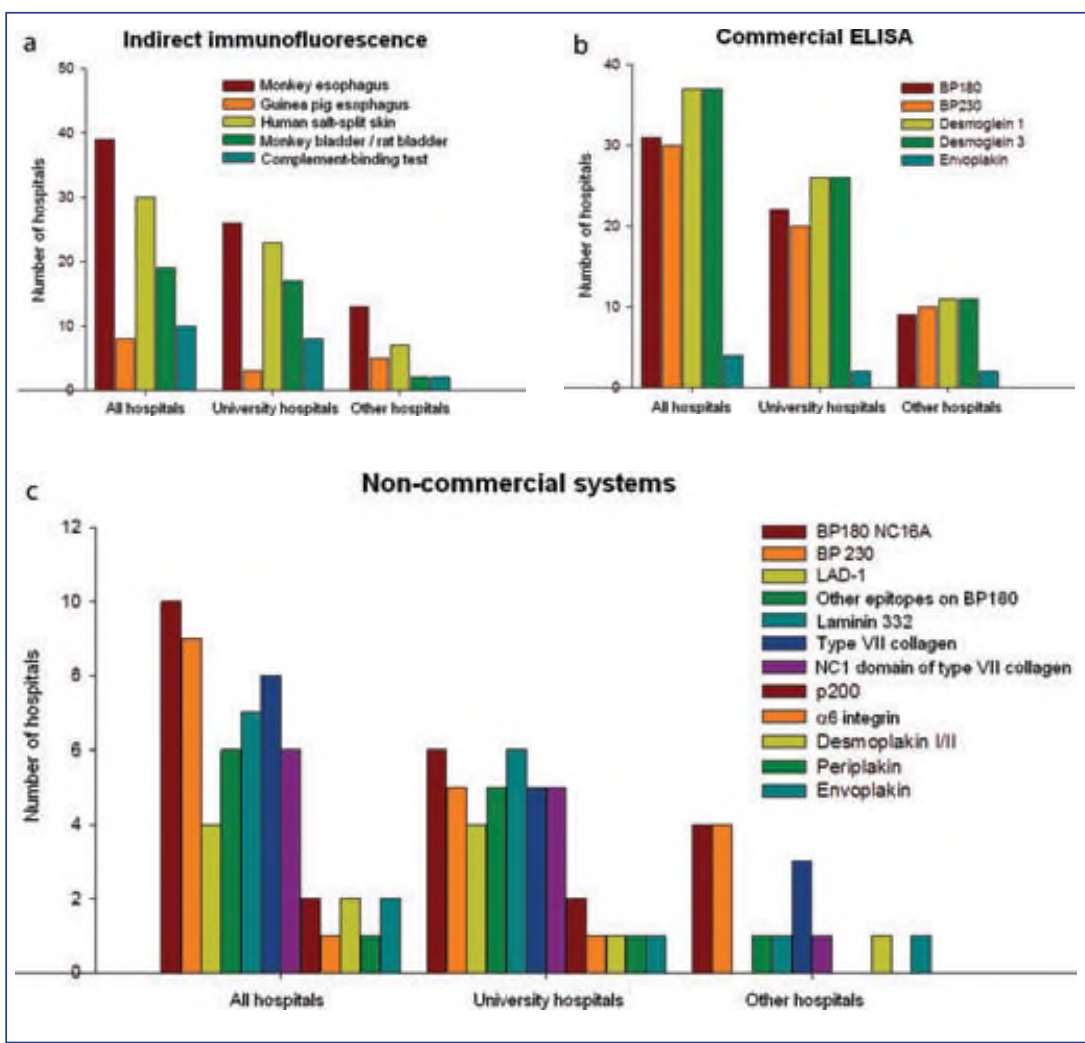

Figure 4: Detailed description of employed serological assays for the diagnosis of autoimmune bullous skin disorders in German dermatology departments. Substrates used for indirect immunofluorescence microscopy (a), autoantigen-specific commercial ELISA systems (b), and autoantigen-specific non-commercial ELISA and immunoblot systems (c).

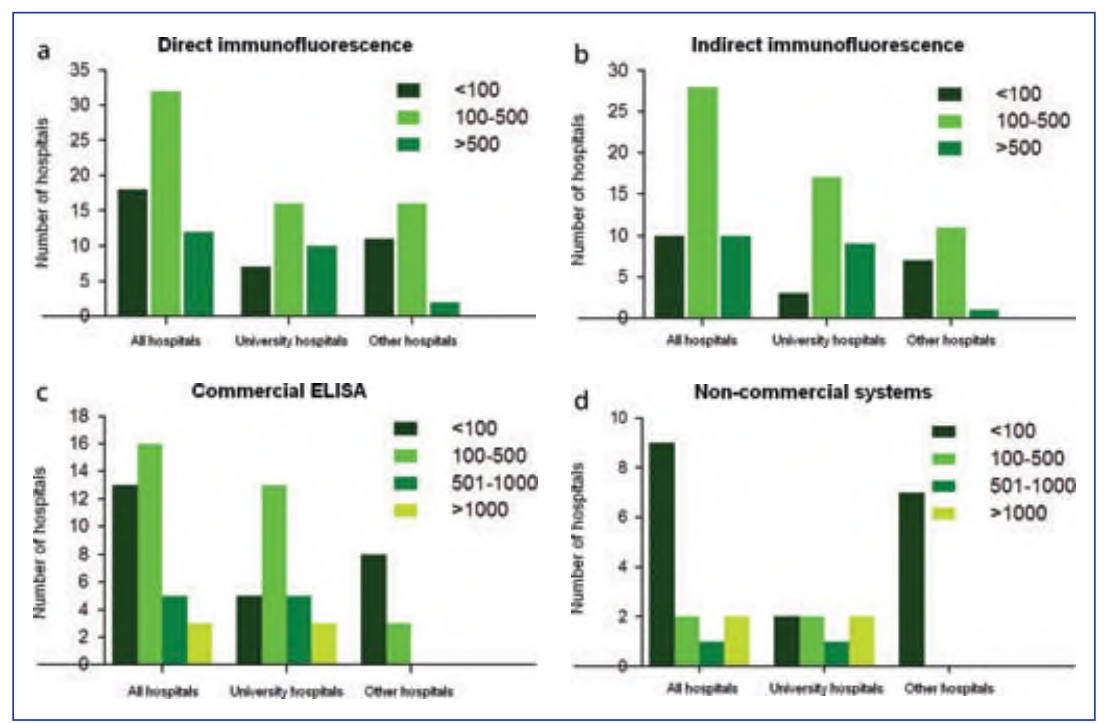

Figure 5: Frequency of diagnostic methods for autoimmune bullous skin diseases in German dermatology departments (a-d).

total collective of all surveyed clinics commercial ELISA-systems were used about twice as often in university departments of dermatology in comparison to nonuniversity dermatology clinics (exception: envoplakin ELISA in 2 university and non-university clinics each) (Figure $4 \mathrm{~b}$ ).
Non-commercial ELISA

\section{and immunoblots}

Non-commercial techniques for the detection of serum autoantibodies were performed in $21 \%$ of the university dermatology clinics (7 of 34) and $23 \%$ of the non-university dermatology clinics
(7 of 31). Here: particularly methods for detection of autoantibodies against BP180, BP230, laminin 332 and type VII collagen were employed (9 \%-15\%). In only a few clinics was detection of autoantibodies against rarer target antigens such as $\alpha 6$ integrin and plakin possible (Figure 4c).

All diagnostic techniques were used more frequently in university departments of dermatology; the proportion of clinics with more than 500 tests yearly for direct IF microscopy was 4 times higher in university clinics than in non-university clinics (29\% vs. $6 \%$ ) and for indirect IF microscopy about 8 times higher $(26 \%$ vs. $3 \%$ ) (Figure $5 \mathrm{a}, \mathrm{b}$ ). More than 500 analyses yearly using commercial and non-commercial ELISA and immunoblot techniques were performed in $26 \%$ and $9 \%$, respectively, of the university clinics $(0 \%$ each for non-university clinics) (Figure $5 \mathrm{c}, \mathrm{d}$ ). The clinics with more than 500 or 1000 tests using direct IF, indirect IF as well as commercially or non-commercially available ELISA/ immunoblot methods are depicted on a geographic overview (Figure 6).

\section{Discussion}

This is the first standardized registration of methods of diagnosing autoimmune bullous dermatoses in German dermatology clinics. A similar study for other countries does not exist. The high return rate of $89 \%$ allows for a representative portrayal and reflects - just as a recent survey on therapy of autoimmune bullous dermatoses did [11] - the great interest in this disease group.

The diagnostic gold standard, direct IF of a perilesional skin (or mucous membrane) biopsy, is performed in practically all surveyed dermatology clinics, in a dozen clinics even more than 500 times yearly. Figure 3 demonstrates that this important method is available in Germany on a nationwide basis. Direct IF is characterized by a high positive predictive value of nearly $100 \%$; only about $10 \%$ of samples from pemphigus patients, for example, are false negative $[9,12]$. Histopathology belongs to routine diagnostics of autoimmune bullous dermatoses, but nevertheless, does not allow for a secure diagnosis of these diseases [13, $14]$, and this was therefore not surveyed. Recently, however, a report appeared on the diagnosis of BP via the detection of C3d deposits in formalin-fixed skin [15]. 


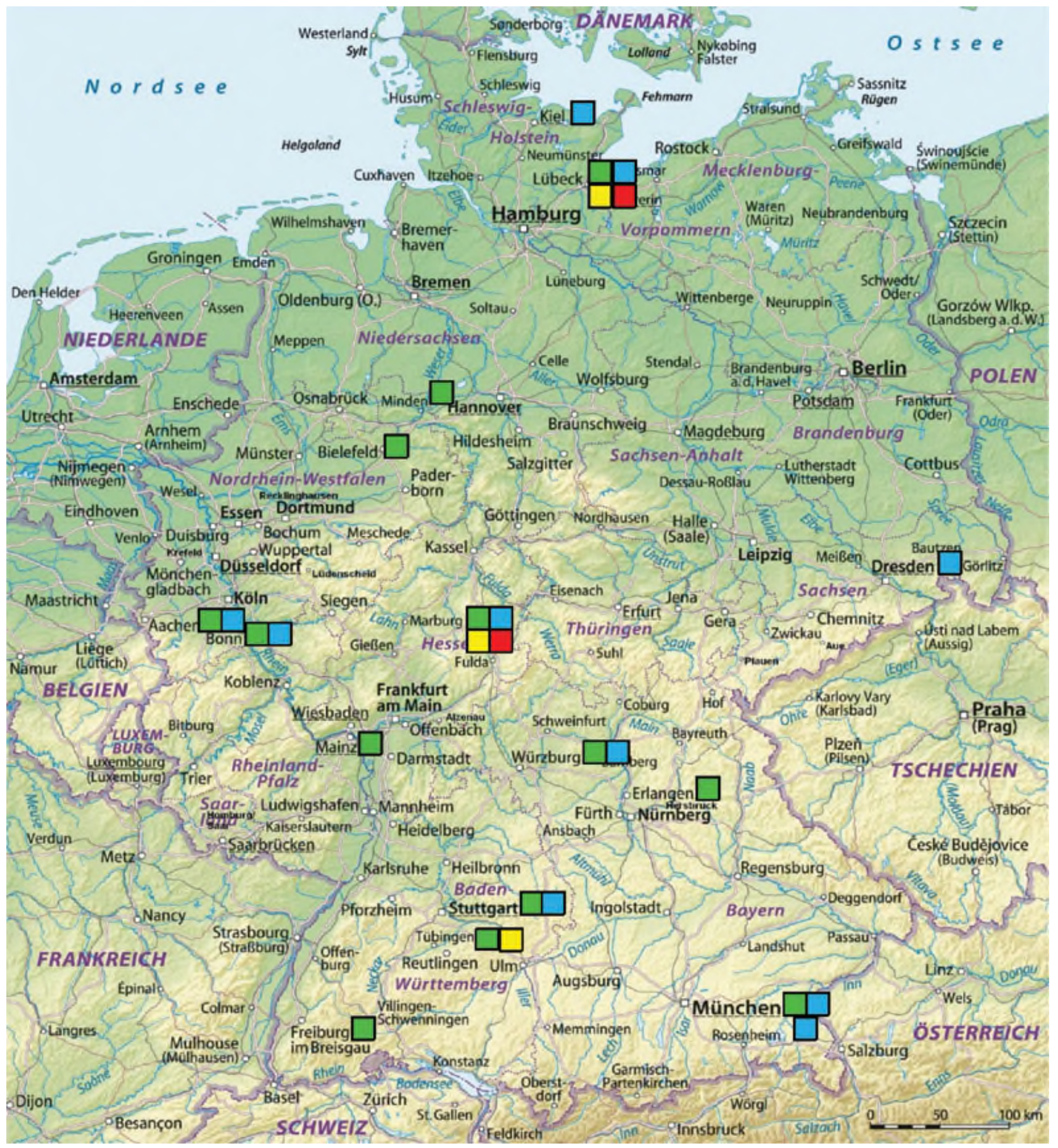

Figure 6: Geographic overview of the dermatology departments with the highest number of diagnostic assays: (green box) > 500 direct IF microscopy/year, (blue box) $>500$ indirect IF microscopy/year, (yellow box) > 1000 commercial ELISA/years, (red box) $>1000$ non-commercial serological assays/year. (License: [http://creativecommons.org/licenses/by-sa/3.0/de/ GNU-Lizenz für freie Dokumentation]).

Indirect IF is a recognized screening method for detection of serum autoantibodies in autoimmune bullous dermatoses. Most sensitive substrates reported were monkey esophagus (for pemphigus vulgaris and dermatitis herpetiformis), guinea pig esophagus (for pemphigus foliaceus), human salt-split (with $1 \mathrm{M} \mathrm{NaCl}$ solution) skin (for pemphigoid diseases and epidermolysis bullosa acquisita as well as - after preincubation with a complement source - for pemphigoid gestationis) as well as monkey and rat bladder (for paraneoplastic pemphigus) [16-22]. The most important screening tests for pemphigus and pemphigoid diseases, indirect IF on monkey esophagus and human salt-split skin are performed in about one-half of the clinics, to be precise, in about two-thirds of university depart- ments of dermatology and one-third of non-university clinics. In 10 clinics over 1000 indirect IF analyses are performed annually, so that an important instrument for the serological diagnosis of autoimmune bullous dermatoses is available on a widespread basis in German dermatology clinics and is employed frequently.

Through the identification and molecular characterization of target antigens the 
development of sensitive and specific ELISA for the detection of circulating autoantibodies has become possible. In the meantime commercial ELISA are available for antibodies against desmoglein 3 (pemphigus vulgaris), desmoglein 1 (pemphigus foliaceus and pemphigus vulgaris), BP180 (bullous pemphigoid, pemphigus gestationis, mucous membrane pemphigoid, lichen planus pemphigoides), BP230 (bullous pemphigoid) and envoplakin (paraneoplastic pemphigus) [23-27]. With the exception of envoplakin ELISA, these are employed in about three-quarters of university and in about one-third of non-university dermatology clinics, which demonstrates the important role that these relatively new techniques already play. In comparison to indirect IF these methods are highly standardized and allow for simple monitoring of the disease course, as the levels of serum antibodies against desmoglein 1 and BP180 and usually also against desmoglein 3 correlate with the disease activity of the respective disease $[25,28-30]$. Already in the survey by Hoffmann et al. these instruments were being used in about one-half of the 32 surveyed clinics for therapy monitoring in BP and pemphigus [11].

Besides these five ELISA various test systems for further target antigens have been established in German dermatology clinics in recent years, among others, for epitopes outside the immunodominant NC16 domain in BP (mucous membrane pemphigoid, linear IgA dermatosis), laminin 332 (mucous membrane pemphigoid), type VII collagen (epidermolysis bullosa acquisita), laminin $\gamma 1$ (anti-p200 pemphigoid), desmocollin (pemphigus) as well as periplakin and desmoplakin I/II (paraneoplastic pemphigus) [31-36]. These methods allow for differentiation between the individual pemphigoid diseases, which is of prognostic and increasingly of therapeutic significance, on the one hand, and on the other it was shown that their combination allows for the detection of autoantibodies in practically all patients with BP and mucous membrane pemphigoid [19, 34]. The non-commercial assays are employed in about one-fifth of the clinics.

Exhaustive further diagnostics of these in the end effect - rare diseases appears widespread, while they - at least in large numbers - are limited to a few special- ized centers (Figure 6). The aim of this paper was to register the health care situation of patients with autoimmune bullous dermatoses with respect to available diagnostics in German dermatology clinics; the methods mentioned therefore do not necessarily have to be performed in the dermatology clinics themselves. Nonetheless, it would be desirable that direct IF as a specialty-specific test continues to be performed in the departments of dermatology to guarantee optimal clinico-pathologic correlation. A challenge for all clinics involved in serological autoimmune diagnostics will surely be future accreditation of the laboratory. It can be expected that the commercialization of further serological test systems will advance the distribution of antigen-specific analyses and thus allow for the continual optimization of the diagnostics of autoimmune bullous dermatoses in Germany.

In summary, diagnostics of autoimmune bullous dermatoses in Germany appears advanced both with respect to availability as well as to the differentiation of the individual diseases. Diagnostics of rare entities is possible via cooperation with several specialized centers.

\section{Acknowledgments}

This paper was supported by the Schleswig-Holstein Cluster of Excellence in Inflammation Research (DFG EXC 306/1).

For participation in this survey we would also like to thank the chairperson of the dermatology clinics in Alzenau, Bad Cannstatt, Berlin (Charité), Bremen, Dortmund, Dresden-Friedrichstadt, Frankfurt/Main, Halle, Heilbronn, Karlsruhe, Kassel, Leipzig, Lüdenscheid, Mannheim, Munich-Schwabing, Nuremberg, Oldenburg and Schwerin (in alphabetical order of the cities).

\section{Conflicts of interest}

None.

\section{Correspondence to}

Prof. Enno Schmidt, MD, PhD

Department of Dermatology

University of Lübeck

Ratzeburger Allee 160

D-23538 Lübeck, Germany

Tel.: +49-451-500-2538

Fax: +49-451-500-2981

E-mail: enno.schmidt@uk-sh.de

\section{References}

1 Bertram F, Bröcker EB, Zillikens D, Schmidt E. Prospective analysis of the incidence of autoimmune bullous disorders in Lower Franconia, Germany. J Dtsch Dermatol Ges 2009; 7(5): 434-40.

2 Hahn-Ristic K, Rzany B, Amagai M, Bröcker EB, Zillikens D. Increased incidence of pemphigus vulgaris in southern Europeans living in Germany compared with native Germans. J Eur Acad Dermatol Venereol 2002; 16(1): 68-71.

3 Jung M, Kippes W, Messer G, Zillikens D, Rzany B. Increased risk of bullous pemphigoid in male and very old patients: A population-based study on incidence. J Am Acad Dermatol 1999; 41(2 Pt 1): 266-8.

4 Chan LS, Ahmed AR, Anhalt GJ, Bernauer W, Cooper KD, Elder MJ, Fine JD, Foster CS, Ghohestani R, Hashimoto T, Hoang-Xuan T, Kirtschig G, Korman NJ, Lightman S, LozadaNur F, Marinkovich MP, Mondino BJ, Prost-Squarcioni C, Rogers RS 3rd, Setterfield JF, West DP, Wojnarowska F, Woodley DT, Yancey KB, Zillikens D, Zone JJ. The first international consensus on mucous membrane pemphigoid: definition, diagnostic criteria, pathogenic factors, medical treatment, and prognostic indicators. Arch Dermatol 2002; 138(3): 370-9.

5 Schmidt E, Della Torre R, Borradori L. Clinical features and practical diagnosis of bullous pemphigoid. Dermatol Clin 2011; 29(3): 427-38.

6 Schmidt E, Zillikens D. Diagnostic and therapy of autoimmune blistering diseases. Dtsch Arztbl Int 2011; 108(23): 399-405.

7 Schmidt E, Zillikens D. Research in practice: diagnosis of subepidermal autoimmune bullous disorders. J Dtsch Dermatol Ges 2009; 7(4): 296-300.

8 Schmidt E, Zillikens D. Modern diagnosis of autoimmune blistering skin diseases. Autoimmun Rev 2010; 10(2): 84-9.

9 Mutasim DF, Adams BB. Immunofluorescence in dermatology. J Am Acad Dermatol 2001; 45(6): 803-22.

10 Eming R, Hertl M. Autoimmune bullous disorders. Clin Chem Lab Med 2006; 44(2): 144-9.

11 Hofmann SC, Kautz O, Hertl M, Sticherling M, Zillikens D, BrucknerTuderman L. Results of a survey of German dermatologists on the therapeutic approaches to pemphigus and 
bullous pemphigoid. J Dtsch Dermatol Ges 2009; 7(3): 227-33.

12 Krasny SA, Beutner EH, Chorzelski TP. Specificity and sensitivity of indirect and direct immunofluorescent findings in the diagnosis of pemphigus. In: Beutner EH, Chorzelski TP, Kumar V: Immunopathology of the Skin. 3rd Edition. New York: John Wiley \& Sons, 1987: 207-48.

13 Rose C, Schmidt E, Kerstan A, ThomaUszynski S, Wesselmann U, Käsbohrer U, Zillikens D, Shimanovich I. Histopathology of anti-laminin 5 mucous membrane pemphigoid. J Am Acad Dermatol 2009; 61(3): 433-40.

14 Rose C, Weyers W, Denisjuk N, Hillen U, Zillikens D, Shimanovich I. Histopathology of anti-p200 pemphigoid. Am J Dermatopathol 2007; 29(2): 119-24.

15 Pfaltz K, Mertz K, Rose C, Scheidegger P, Pfaltz M, Kempf W. C3d immunohistochemistry on formalin-fixed tissue is a valuable tool in the diagnosis of bullous pemphigoid of the skin. J Cutan Pathol 2010; 37(6): 654-8.

16 Hahn K, Kippes W, Amagai M, Rzany B, Bröcker EB, Zillikens D. [Clinical aspects and immunopathology in 48 patients with pemphigus]. Hautarzt 2000; 51(9): 670-7.

17 Kippes W, Schmidt E, Roth A, Rzany B, Bröcker EB, Zillikens D. [Immunopathologic changes in 115 patients with bullous pemphigoid]. Hautarzt 1999; 50(12): 866-72.

18 Mouquet H, Drenovska K, Lartigue A, Joly P, Drouot L, Thomas M, Tron F, Gilbert D. Detection and characterization of anti-envoplakin linker autoantibodies in paraneoplastic pemphigus using specific bead-based assay. Clin Immunol 2008; 129(2): 304-12.

19 Schmidt E, Skrobek C, Kromminga A, Hashimoto T, Messer G, Bröcker EB, Yancey KB, Zillikens D. Cicatricial pemphigoid: $\operatorname{IgA}$ and $\operatorname{IgG}$ autoantibodies target epitopes on both intra- and extracellular domains of bullous pemphigoid antigen 180. Br J Dermatol 2001; 145(5): 778-83.

20 Sitaru C, Powell J, Messer G, Bröcker EB, Wojnarowska F, Zillikens D. Immunoblotting and enzyme-linked immunosorbent assay for the diagnosis of pemphigoid gestationis. Obstet Gynecol 2004; 103(4): 757-63.

21 Sabolinski ML, Beutner EH, Krasny S, Kumar V, Huang J, Chorzelski TP, Sampaio S, Bystryn JC. Substrate specificity of anti-epithelial antibodies of pemphigus vulgaris and pemphigus foliaceus sera in immunofluorescence tests on monkey and guinea pig esophagus sections. J Invest Dermatol 1987; 88(5): 545-9.

22 Ghohestani R, Kanitakis J, Nicolas JF, Cozzani E, Claudy A. Comparative sensitivity of indirect immunofluorescence to immunoblot assay for the detection of circulating antibodies to bullous pemphigoid antigens 1 and 2 . Br J Dermatol 1996; 135(1): 74-9.

23 Ishii K, Amagai M, Hall RP, Hashimoto T, Takayanagi A, Gamou S, Shimizu N, Nishikawa T. Characterization of autoantibodies in pemphigus using antigen-specific enzyme-linked immunosorbent assays with baculovirus-expressed recombinant desmogleins. J Immunol 1997; 159(4): 2010-7.

24 Probst C, Schlumberger W, Stöcker W, Recke A, Schmidt E, Hashimoto T, Zhu XJ, Zillikens D, Komorowski L. Development of ELISA for the specific determination of autoantibodies against envoplakin and periplakin in paraneoplastic pemphigus. Clin Chim Acta 2009; 410(1-2): 13-8.

25 Schmidt E, Dähnrich C, Rosemann A, Probst C, Komorowski L, Saschenbrecker S, Schlumberger W, Stöcker W, Hashimoto T, Bröcker EB, Recke A, Rose C, Zillikens D. Novel ELISA systems for antibodies to desmoglein 1 and 3: correlation of disease activity with serum autoantibody levels in individual pemphigus patients. Exp Dermatol 2010; 19(5): 458-63.

26 Sitaru C, Dähnrich C, Probst C, Komorowski L, Blöcker I, Schmidt E, Schlumberger W, Rose C, Stöcker W, Zillikens D. Enzyme-linked immunosorbent assay using multimers of the 16th non-collagenous domain of the BP180 antigen for sensitive and specific detection of pemphigoid autoantibodies. Exp Dermatol 2007; 16(9): 770-7.

27 Yoshida M, Hamada T, Amagai M, Hashimoto K, Uehara R, Yamaguchi K, Imamura K, Okamoto E, Yasumoto $S$, Hashimoto T. Enzyme-linked immunosorbent assay using bacterial recombinant proteins of human BP230 as a diagnostic tool for bullous pemphigoid. J Dermatol Sci 2006; 41(1): 21-30.

28 Harman KE, Seed PT, Gratian MJ, Bhogal BS, Challacombe SJ, Black MM. The severity of cutaneous and oral pemphigus is related to desmoglein 1 and 3 antibody levels. Br J Dermatol 2001; 144(4): 775-80.
29 Schmidt E, Obe K, Bröcker EB, Zillikens D. Serum levels of autoantibodies to BP180 correlate with disease activity in patients with bullous pemphigoid. Arch Dermatol 2000; 136(2): 174-8.

30 Thoma-Uszynski S, Uter W, Schwietzke S, Hofmann SC, Hunziker T, Bernard P, Treudler R, Zouboulis CC, Schuler G, Borradori L, Hertl M. BP230- and BP180-specific auto-antibodies in bullous pemphigoid. J Invest Dermatol 2004; 122(6): 1413-22.

31 Groth S, Recke A, Vafia K, Ludwig RJ, Hashimoto T, Zillikens D, Schmidt E. Development of a simple ELISA for the detection of utoantibodies in anti-p200 pemphigoid. Br J Dermatol 2011; 164(1): 76-82.

32 Lazarova Z, Sitaru C, Zillikens D, Yancey KB. Comparative analysis of methods for detection of anti-laminin 5 autoantibodies in patients with antiepiligrin cicatricial pemphigoid. J Am Acad Dermatol 2004; 51(6): 886-92.

33 Müller R, Heber B, Hashimoto T, Messer G, Müllegger R, Niedermeier A, Hertl M. Autoantibodies against desmocollins in European patients with pemphigus. Clin Exp Dermatol 2009; 34(8): 898-903.

34 Di Zenzo G, Thoma-Uszynski S, Fontao L, Calabresi V, Hofmann SC, Hellmark T, Sebbag N, Pedicelli C, Sera F, Lacour JP, Wieslander J, Bruckner-Tuderman L, Borradori L, Zambruno G, Hertl M. Multicenter prospective study of the humoral autoimmune response in bullous pemphigoid. Clin Immunol 2008; 128(3): 415-26.

35 Csorba K, Schmidt S, Florea F, Ishii N, Hashimoto T, Hertl M, Kárpáti $S$, Bruckner-Tuderman L, Nishie W, Sitaru C. Development of an ELISA for sensitive and specific detection of IgA autoantibodies against BP180 in pemphigoid diseases. Orphanet J Rare Dis 2011; 6(1): 31.

36 Saleh MA, Ishii K, Kim YJ, Murakami A, Ishii N, Hashimoto T, Schmidt E, Zillikens D, Shirakata Y, Hashimoto K, Kitajima Y, Amagai M. Development of NC1 and NC2 domains of Type VII collagen ELISA for the diagnosis and analysis of the time course of epidermolysis bullosa acquisita patients. J Dermatol Sci 2011; 62(3): 169-75.

37 Schmidt E, Zillikens D. Diagnosis and Treatment of Patients with Autoimmune Bullous Disorders in Germany. Dermatol Clin 2011; 29(4): 663-71. 